MODELING, IDENTIFICATION AND CONTROL, 1995, VOL. 16, NO. 1, 3-33

doi:10.4173/mic.1995.11

\title{
Modeling and simulation of an anode carbon baking furnace
}

\author{
Ø. GUNDERSEN $\dagger$ and JENS G. BALCHEN $\dagger$
}

Keywords: First principles modeling, distributed thermal batch process, heat transfer, combustion, pyrolysis

The anode temperature profile in a Hydro Aluminium baking furnace is obtained by solving the three dimensional heat equation. The main heat transfer and chemical processes are taken into account. Due to symmetry, one half of a pit is modeled. Along the gas path, submodels are derived for the under-pit area, pit area and under-lid area. For the gas flow, a stationary model is derived, whereas the heat equations are dynamically solved. The numerical model is derived from the control volume formulation.

\section{Introduction}

Large quantities of carbon anodes are spent in order to produce aluminium. Theoretical consumption of carbon is approximately $334 \mathrm{~kg}$ for each ton of metal. However, practical net consumption is in the order of $400 \mathrm{~kg}$ per ton due to non-ideal operation of the aluminium smelters. Usually, the anodes are manufactured locally at the smelters in separate installations (Wilkening 1993). Prior to baking, green (unbaked) anodes are made as a blend of calcined petroleum coke heat treated to approximately $1300^{\circ} \mathrm{C}$ and coal tar pitch. The pitch is mixed with a carefully sized filler coke aggregate. Thus, coal tar pitch is used as binder and calcined petroleum coke is used as filler. According to nominal recipes, there is in the order of $20 \%$ coal tar pitch in the mixture of coke and pitch. The so-called green paste is moulded into a block of green anode. Typical weight of the green block is between 650 and $1000 \mathrm{~kg}$. The green anode is heat treated for about 200 hours in specially designed furnaces, so-called ring furnaces.

\subsection{Types of ring furnaces.}

Open- (horizontal-) and vertical- (closed-, Riedhammer-) flue ring furnaces are commonly used for anode baking. In horizontal furnaces, gases flow horizontally along the flues. Vertical baffles in the flues cause the gas flow to fluctuate vertically, which contributes to a uniform heat treatment of the anodes. In each pit, the anodes are covered with packing coke with no separation from ambient air. In vertical furnaces, each section is covered with a lid giving a closed gas path from one section to the other. Both kinds of furnaces comprise several sections arranged in two parallel lines and connected head to tail in a ring fashion. There are normally between 28 and 48 sections in a ring surface. The construction principle of a section in each of these furnaces is shown in Fig. 2.

Received 6 June 1994.

† Department of Engineering Cybernetics, The Norwegian Institute of Technology, 7034 Trondheim-NTH, Norway. e-mail: Oeyvind.Gundersen@itk.unit.no

A preliminary version of this paper was presented at the SIMS` 93 Simulation Conference, Kongsherg, June 9-11, 1993. 
In this article, a closed furnace of Hydro Aluminium type is studied. The construction principle of a section of such a furnace shown in Fig. 3 is a modification of the conventional vertical Riedhammer furnace. As seen in the figure, the gas flow pattern is modified compared to a conventional closed furnace. In fact, Hydro Aluminium furnace technology combines features from both open and closed ring furnace technology (Jakobsen, Lid and Schreiner 1987).

\subsection{Description of the baking process}

Ring furnace operation is the most expensive step in the production of anodes. During baking, chemical and physical bonds between petroleum coke and pitch develop (Jones and Bart 1990). Each section is divided into several pits with anodes stacked in each pit. In a Hydro Aluminium type furnace, anodes are stacked in three layers. The pits are separated by pit walls, in which the hot gases flow. Approximately 100 anodes are loaded in each section. The anodes are surrounded by packing coke, which gives physical support and acts as a heat transfer medium. In the preheating and heating sections, hot gases flow in the pit wall flues for transmission of heat through the brickwork and packing of coke to the anodes. In the cooling sections, ambient air is used for cooling the anodes in a similar way. At the front of the fire-train (this is a chain of ring furnace sections operating in different parts of the baking cycle and linked together as a series of batch processes with a common gas flow between them), a draught fan maintains the gas flow through the chain of sections. Inflowing ambient air enters the last section in the fire-train and is preheated by cooling the anodes. The heated air supplies oxygen for the combustion of oil in the heating sections. In the preheating sections, cold anodes are heated by hot gas and combustion of hydrocarbon volatiles coming from the binder pitch. Thus, the heat comes from combustion of liquid or gaseous fuel as well as from hydrocarbon volatiles; mainly tar, methane and hydrogen. Some heat also comes from combustion of the packing coke covering the anodes. The anodes remain stationary in the pits, but the burners are moved at regular intervals in time known as the fire-step (typically 22-36 hours). At each fire-step, one section filled with anodes is connected to the front of the fire-train, one section is linked out of the chain of sections and the anodes are unloaded from the pits. Typically, two fire-trains are running on each furnace. A typical fire cycle in a section is shown in Fig. 4. Each section passes a sequence of natural preheat, pitch burn, forced heat by fuel combustion, heating at peak temperature, and cooling. In principle, the ring furnace acts as a heat exchanger with preheating, heating, and cooling sections linked in series.

\subsection{Previous work}

Ring furnaces are large industrial units operating in batch mode. Experiments are both time consuming and expensive due to large time constants in the process. This has promoted design and computer implementation of mathematical models for the baking process.

The first articles on ring furnace modeling appeared in 1980, and a great number of contributions have appeared since then. Furman and Martirena (1980), Monica, Marletto and Martirena (1983) and Hurlen, Lid, Naterstad and Utne (1981) developed models for a conventional vertical flue ring furnace (Riedhammer type). Keller and Disselhorst (1981) presented a model for a horizontal flue ring furnace. In a series of articles mainly discussing horizontal ring furnaces, Bui and coworkers have contributed significantly to the understanding of the baking process. Among several articles dealing 


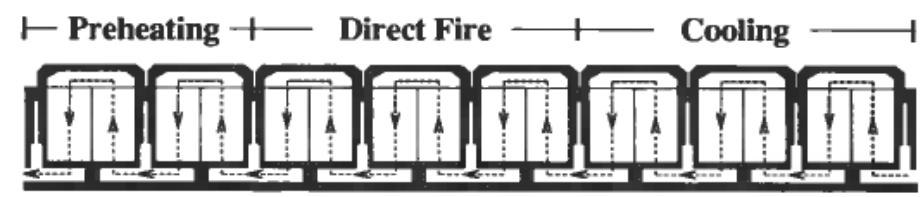

Figure 1. Fire-train (zone) on a vertical ring furnace of Hydro Aluminium type.

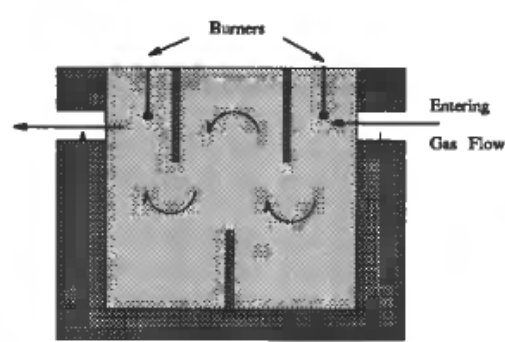

Comventional

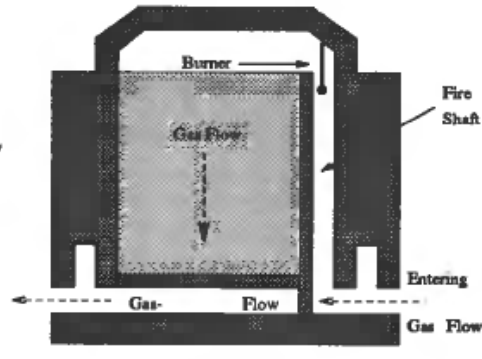

Conventional

Cloeed RIng Purnace

Figure 2. Construction principle of open (left) and conventional closed (right) ring furnaces.

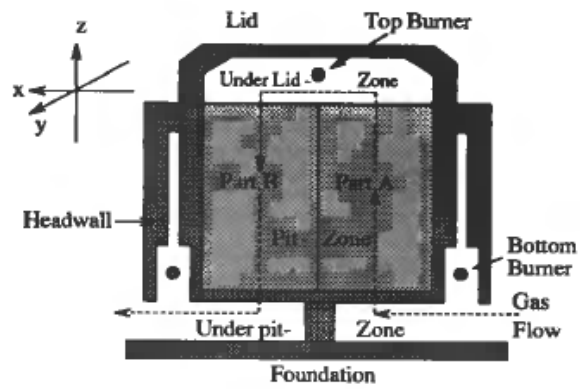

Figure 3. Side view ( $x z$-plane) of Hydro Aluminium ring furnace section. During ring furnace operation in the order of 7 to 12 , sections are linked in series and a common gas flow travels the arrowed path through each section.

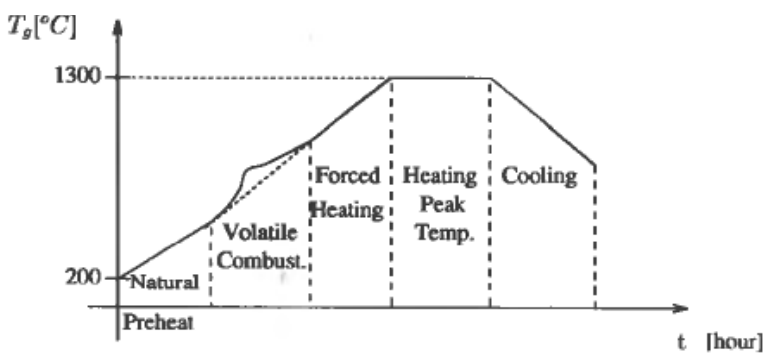

Figure 4. Typical fire cycle for ring furnace section. 
with mathematical modeling of horizontal flue ring furnaces; the following may be mentioned: Bui, Charette and Bourgeois (1984) and Bui, Charette and Bourgeois (1987). Equations for temperature profiles in both gas and solids, volatile release and combustion as well as air-inleakage are solved. Based on experiences from modeling of horizontal furnaces, Bourgeois, Bui, Charette, Sadler and Tomsett (1990) describe a computer model for a Riedhammer type furnace.

In some applications, commercially available software has been used for implementing the models. Stevenson (1988) studied gas velocity profiles in flues of a horizontal furnace using the PHOENICS fluid flow modeling package. The same tool was used by Bui, Peter, Charette, Tomsett and Potocnik (1992) in studies of under-lid heat transfer and combustion in a conventional ring furnace. The use of other packages in ring furnace modeling (FLUENT, ANSYS etc.) has not yet been reported in the literature.

Until now, mathematical models of Hydro Aluminium ring furnaces has not been published. In this article, a simulation model for this type of ring furnace is presented. A three dimensional temperature field in the solid materials as well as the properties and temperatures along the gas path are calculated. The numerical model is implemented in the $\mathrm{C}$-programming language.

\section{System decomposition and modeling strategy}

A ring furnace is a complex system to model due to a complex but regular construction geometry as well as the complexity of the physical and chemical transformations taking place in the anode binder pitch during baking. A ring furnace process model has to be based on a systematic subdivision of the process into tractable units. Within these units, qualified simplifications must be made.

\subsection{System decomposition}

In a ring furnace, two subsystems interact with each other: The flue gases exchange energy with the solid materials of brickwork, packing coke and anodes. Stevenson $(1988$, p. 307) suggests the following decomposition of each position along the flues of a ring furnace:

(1) Combustion flues with flowing gases.

(2) Ring furnace solid materials:

- Brickwork flue walls.

- Packed bed (pit) of granular coke and green, partly carbonized or baked anodes.

As shown in Fig. 5, the main interaction between these systems is energy transfer. Also, mass transfer occurs as transport of the released volatile gases to the flues. This transfer of mass is an important source of energy during baking, since the volatile gases are combusted in the flues.

Due to the geometric structure of the gas path through a furnace section, a convenient division of the gas path into six zones is shown in Fig. 3.

- Zone 1: Headwall (in part $A$ )

- Zone 2: Under-pit in part $A$

- Zone 3: Vertical flue channels in part $A$ 


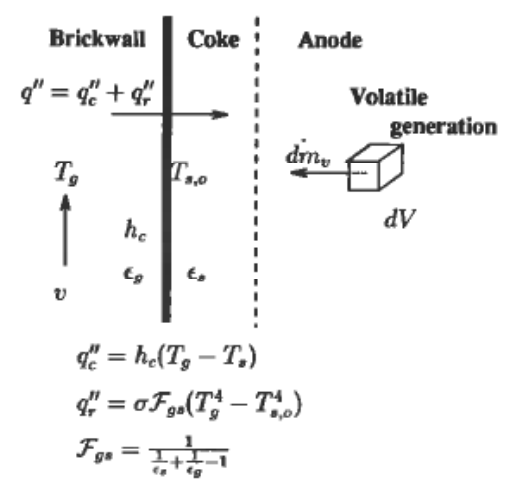

Figure 5. Ring furnace system decomposition.

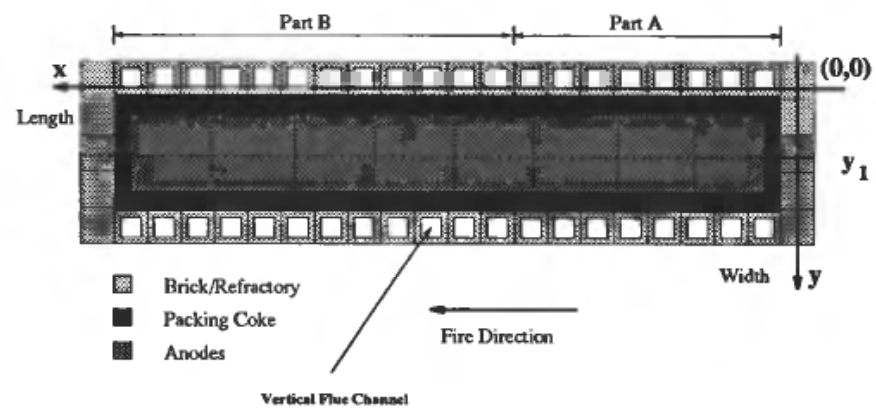

Figure 6. Pit seen from the $x y$-plane. Each section contains in the order of 5 to 7 adjacent pits. A dividing wall in the under-pit region forces the gas flow vertically upwards in part $A$ of the pits. Each section is covered by a lid which forces the gas to flow downwards in the vertical flues of part $\boldsymbol{B}$. Note the definition of coordinate axes.

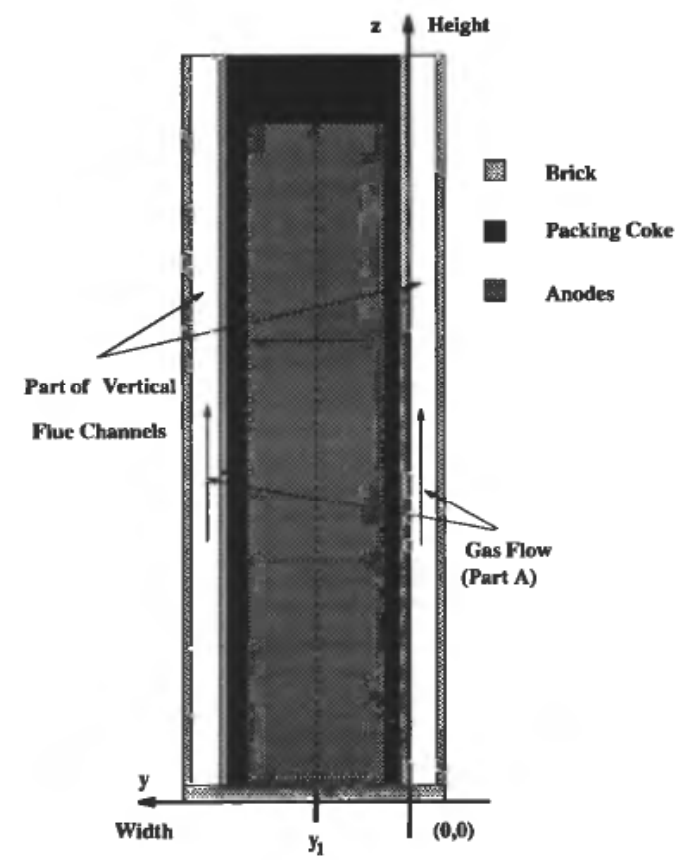

Figure 7. Pit seen from the $y z$-plane. The vertical flue channels belong to part $A$ of the pit since the gas flow is vertically upwards. In part $B$, gas flow is vertically downwards. Note the definition of coordinate axes. 
- Zone 4: Under-lid

- Zone 5: Vertical flue channels in part $B$

- Zone 6: Under-pit in part $B$

The same technique was used by Bourgeois et al. (1990) in modeling the gas path of conventional closed furnace. Details of one pit with flue channels seen from the $x y$ - and $y z$-plane are given in Figs 6 and 7 respectively. As can be seen in Fig. 3, there is a dividing wall approximately in the middle of the section in the under-pit zones. The dividing wall is positioned normal to the gas flow and separates part $A$ and part $B$. The wall's purpose is to force the gas coming from the headwall in part $A$ to enter the vertical flue channels in part $A$. Thus, in the flues of part $A$ the gas flow is vertically upwards. After entering the under-lid region in plain style, the gas is forced to flow downwards in the vertical flue channels in part $B$ and finally to enter the under-pit in part $B$. Thus, the terms part $A$ and part $B$ are used to describe the parts of the pit with vertically upward and downward gas flow respectively. Convective and radiative heat transfer between solids and gases occurs at the brick surface in each zone.

\subsection{Modeling strategy}

Focus is put on heat balance calculations for solid materials and combustion gas. The heat balances are derived from classic first principles modeling. Bird, Steward and Lightfoot (1960) give a rigorous derivation of the fundamental energy equation. For a general medium with heat conduction and internal energy sources, the simplified energy balance is:

$$
\frac{\partial(\rho u)}{\partial t}=-\nabla q^{\prime \prime}-\nabla(\rho u \underline{v})+S+\tilde{Q}
$$

where $u(\mathrm{~J} / \mathrm{kg})$ is specific internal energy, $q^{\prime \prime}\left(\mathrm{W} / \mathrm{m}^{2}\right)$ is the heat flux, and $\underline{v}(\mathrm{~m} / \mathrm{s})$ is the velocity of the medium. $S\left(\mathrm{~W} / \mathrm{m}^{3}\right)$ is a heat source (sink) term, and $\tilde{Q}$ is a heat transfer term. This equation is the basis for the ring furnace heat balances.

During baking, the anodes act as a sink since energy is needed in the chemical transformations of the binder from pitch into coke. In modeling the flue gas heat balance, one commonly considers three energy sources and sinks (Bourgeois et al. 1990) as follows:

- Heat sources:
(1) Fuel-oil
(2) Pitch volatiles
(3) Packing coke

- Heat sinks:

(1) Solid materials of brick, coke, and anodes

(2) Exhaust combustion gases

(3) Heat losses to surrounding via cover, section sidewalls and foundation.

In this work, we only consider fuel oil and pitch volatiles as energy sources since the cooling part of the anode baking cycle is not modeled, and packing coke combustion is most significant during cooling. The heat balances are established via first principles modeling. However, the model for generation of volatiles is based on empirical data 
found in the literature. Volatile transport in the anodes and the coke bed is not modeled and the released volatiles are instantaneously combusted in the flues.

Both for the gas and solid materials heat balances, several thermally dependent properties are needed. For the solid materials, data was partly found in the literature. Average gas property data along the gas path were calculated from well known correlations and tabulated values for properties of the gas compounds.

Due to the large time constants in the solid temperature field, a dynamic heat balance is calculated for the solids. On the other hand, gas phenomena have small time constants, and a stationary model gives satisfactory results as well as reduced computing time (Stevenson 1988, p. 307).

\section{Modeling of solid materials phenomena}

During baking, there is a continuous transformation of the liquid pitch into binder coke under the release of volatile gases. This transformation is thermally induced and has to be controlled to arrive at anodes with the desired properties. Also, the heat from the volatiles is returned to the process during combustion in the flues. Therefore, it is of importance to have insight into the shape of the temperature profile in the anodes.

\subsection{Thermal properties of solid materials}

For calculation of the solid materials heat balance, data for density $\rho$, specific heat capacity $c_{p}$, and thermal conductivity $k$ for the brickwork, packing coke, and anodes are needed.

\subsubsection{Brickwork}

During heating, the brickwork expands and gives a reduced brickwork density. If $\alpha$ is the coefficient of thermal expansion, the temperature dependent density is given by:

$$
\rho=\rho_{0}\left(1+\alpha\left(T-T_{0}\right)\right)
$$

where $T_{0}$ is the room temperature. For the brickwork, $\alpha$ is in the order of $10^{-4} 1 / \mathrm{K}$. For the heat capacity and thermal conductivity, polynomial functions of temperature were used to describe these properties' temperature dependency. Low order polynomials (2nd or 3rd order) were used to fit the brickwork data.

\subsubsection{Packing coke}

Calcined coke with approximately constant bulk density over the baking temperature interval is used as packing coke. The bulk density includes inter- and intraparticular voids of the coke bed surrounding the anodes. These voids allow for a significant radiation heat flux in the coke bed at high temperatures. This could be modeled by adding a radiation term on the right hand side of (7). According to Froment and Bischoff (1990), this term is generally lumped with the heat conduction term by application of an effective thermal conductivity. Also, for the coke bed, polynomial functions of temperature were used for the specific heat capacity and thermal conductivity.

\subsubsection{Anodes}

The density of the porous anode depends on the transformations taking place in the pitch fraction of the anode. In the pitch fraction, a crystalline structure grows during heat treatment and increases the degree of order and therefore density. The heat of 
vaporization and heat of reaction was not explicitly modeled in the heat equation, but apparent values of specific heat capacity and thermal conductivity were used to model the total effect of heat conduction and heat of chemical reactions.

\subsubsection{Structure of property correlations}

To summarize, the density, specific heat capacity, and thermal conductivity depend on the temperature and thus on time. To express this temperature dependency, properties are modeled with polynomial functions of temperature as follows:

$$
\begin{aligned}
\rho_{i} & =\sum_{j=0}^{n a_{i}} a_{i j} T^{j} \\
c p_{i} & =\sum_{j=0}^{n b_{i}} b_{i j} T^{j} \\
k_{i} & =\sum_{j=0}^{n c_{i}} c_{i j} T^{j}
\end{aligned}
$$

where $i=$ brick, coke, and anode. Some of the functions were derived from least squares polynomial fit to data found in the literature.

\subsection{Heat conduction in the pit}

Heat conduction in a solid material is governed by Fourier's law:

$$
\nabla q^{\prime \prime}=-k \nabla T
$$

Substitution of Fourier's law and $\underline{v}=0$ in (1) gives:

$$
\frac{\partial\left(\rho_{s} u_{s}\right)}{\partial t}=\nabla(k \nabla T)+S+\tilde{Q}
$$

where $\rho_{s}$ and $u_{s}$ denote density and specific internal energy of the solid material. For solid materials, the constant volume- and constant pressure specific heat capacities are approximately equal, and we have $d u=c_{p} d T$. Also, density changes are negligible or very small. Then we have $\left|\rho c_{p}\right| \gg u(\partial \rho / \partial T)$. The heat equation without source term is based on these assumptions:

$$
\rho c_{p} \frac{\partial T}{\partial t}=\nabla(k \nabla T)
$$

In this case, the equation is non-linear due to the temperature varying properties. One should also note that the property functions are spatially discontinuous due to a regular but complex geometric structure of the pit where brickwork and coke surround the anodes. It should also be noted that (7) does not imply conservation of energy in cases when $\partial \rho / \partial t \neq 0$ but most frequently (7) is a good approximation of a conservative energy balance. The validity (7) for calculation of the ring furnace temperature profile is not obvious; an explanation seems necessary.

For the brickwork and coke bed, density changes are negligible. In the coke and anode, gases and solids coexist due to the release and transport of volatiles from anodes to the combustion flues. Thus, we have a heterogeneous system of two phases in which separate mass and energy balances for the gas and solids could be derived. However, a uniform temperature is assigned to each control volume. The volatile mass transport takes place at velocities in the order of $10^{-4} \mathrm{~m} / \mathrm{s}$ (Dernedde, Charette, Bourgeois and 


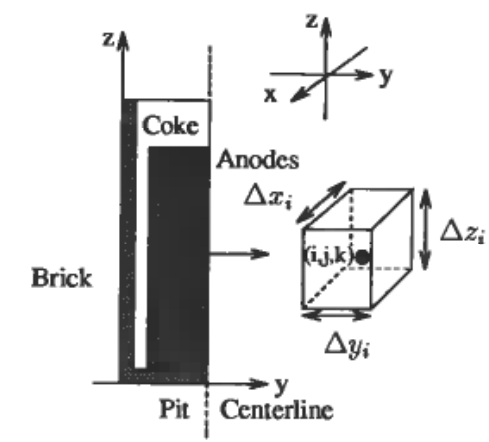

Figure 8. Solid control volume seen from $x y$-plane.

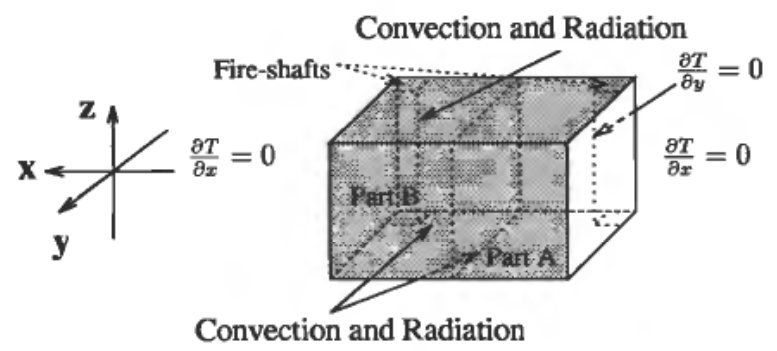

Figure 9. Specified boundary condition for a half pit.

Castonguay 1986). The energy contribution due to convective or diffusive transport of pitch volatiles in the coke bed and anode is therefore neglected. Energy transfer in connection with possible chemical reactions in the diffusing gases is assumed negligible. Then (7) is a good approximation for the temperature calculations in brickwork and packing code. For the anode, it can be shown that a source term should be included to cope with the energy consumed during generation of the volatiles. However, most common in ring furnace modeling is the lumping of this source term into an effective heat capacity for the anode material. Therefore, (7) can be used for studying the overall pit temperature field.

Heat conduction in pit refractory, coke, and anodes is modeled in three dimensions. In each section, there are six pits. Due to symmetry, the three dimensional temperature field is calculated for half a pit using the following equation:

$$
\rho c_{p} \frac{\partial T}{\partial t}=\frac{\partial}{\partial x}\left(k \frac{\partial T}{\partial x}\right)+\frac{\partial}{\partial y}\left(k \frac{\partial T}{\partial y}\right)+\frac{\partial}{\partial z}\left(k \frac{\partial T}{\partial z}\right)
$$

The control volume as seen from the $y z$-plane is shown in Fig. 8. It has the shape of a parallelepiped with geometry as follows: the height $L_{z}$ (z-direction) goes from the pit refractory bottom to the coke bed top. The extension in width $L_{x}(x$-direction) is from centre to centre of adjacent headwalls. The thickness $L_{y}(y$-direction) is from the surface of the brickwork of the pit wall to the centre of the pit. Boundary conditions for the six surfaces of the solid pit must be specified;

(1) The $x z$-plane:

- The $x z$-plane through the pit centre is an adiabatic plane (pit symmetry): 


$$
\left.\frac{\partial T}{\partial y}\right|_{y=L_{y}}=0
$$

- At the $x z$-plane parallel to the pit wall there is convective and radiative heat transfer (vertical flues):

$$
-\left.k \frac{\partial T}{\partial y}\right|_{y=0}=h_{c}\left(T_{g}-\left.T\right|_{y=0}\right)+\mathscr{F}_{g s} \sigma\left(T_{g}^{4}-\left.T\right|_{y=0} ^{4}\right)
$$

where $\mathscr{F}_{g s}$ is the radiation factor between gas and brick surface.

(2) For the $x y$-planes through pit top (under-lid) and bottom (under-pit), there is convective and radiative heat transfer. The heat flux expressions are similar to the boundary conditions for the $x z$-plane except for the addition of a term representing heat transfer between the surfaces facing each other, as shown in Subsection 4.2.

(3) Constituting a part of the headwall, a vertical fire-shaft with a rectangular cross section is used for firing in part $A$ (see Fig. 9). In the numerical model, outblocking is used for modeling the presence of the fire-shaft. For the rest of the headwall, an adiabatic boundary condition is assumed. (In another case studied, the whole $y z$-plane (without outblocking) through headwall centre is assumed adiabatic).

$$
\begin{aligned}
& \left.\frac{\partial T}{\partial x}\right|_{x=0}=0 \\
& \left.\frac{\partial T}{\partial x}\right|_{x=L_{x}}=0
\end{aligned}
$$

Contact resistance between the different materials in the pit was neglected.

\subsection{Heat loss through furnace lid and foundation}

Heat loss through the foundation was modeled as a two dimensional phenomenon in the $x z$-plane. For foundation refractory facing the combustion gas, convective and radiative heat transfer boundary conditions were specified. For the foundation bottom, a constant temperature was specified.

The curved nature of the furnace lid was neglected and the lid was assumed to be an infinite plate. Thus, heat conduction boundary effects could be neglected. A one-dimensional heat conduction model was used due to the assumption of uniform temperature in the gas under the lid and the infinite plate assumption. The lid boundary heat fluxes were specified as follows: at the lid surface facing the combustion gases, there is forced convection and radiation heat transfer. At the external lid surface, free convection- and radiation heat transfer were modeled.

\subsection{Pyrolysis of binder pitch}

The use of calcined petroleum coke implies that no chemical and physical changes occur in the filler coke during baking. The purpose of the baking process is to convert the coal tar binder pitch into high quality binder coke which holds the filler coke particles together.

\subsubsection{Pyrolysis chemistry}

The pitch softens at approximately $100^{\circ} \mathrm{C}$. Volatile hydrocarbon compounds 
evaporate and liquid crystal growth takes place between approximately $300^{\circ} \mathrm{C}$ and $600^{\circ} \mathrm{C}$. At temperatures above $600^{\circ} \mathrm{C}$, further crystal growth takes place in the solidified pitch fraction under the release of methane and hydrogen due to polymerization. The carbonization process finishes between $1100^{\circ} \mathrm{C}$ and $1300^{\circ} \mathrm{C}$. During carbonization, the binder pitch is converted to a pitch coke under the release of volatile gases. The volatiles are usually divided into two groups:

(1) Condensable hydrocarbons (mainly polycyclic aromatic hydrocarbons; tar)

(2) Noncondensable hydrocarbons (mainly methane and hydrogen)

\subsubsection{Pyrolysis model}

Traditionally, thermogravimetry has been used to estimate the kinetic parameters of pyrolysis. We use a kinetic model derived by Tremblay and Charette (1988) in which simultaneous thermogravimetry and gas chromatogaphy were performed to measure weight loss curves of tar, hydrogen, and methane. The fractional conversion of volatile compounds are modeled with Arrhenius-like expressions:

$$
\begin{aligned}
\frac{d X_{i}}{d t} & =k_{i}\left(1-X_{i}\right)^{n_{i}} \\
k_{i} & =k_{0, i} \exp \left(-E_{i} / R T\right)
\end{aligned}
$$

$X_{i}$ is the fractional conversion of volatile component $i$ where $i$ denotes tar, methane or hydrogen. $k_{0, i}$ and $E_{i}$ denote apparent pre-exponential factor and apparent activation energy respectively. $n_{i}$ is the apparent reaction order. Relevant data for the anode baking process was taken from Tremblay and Charette (1988). Based on the equations for $d X_{i} / d t$, an expression for the volatile emission rate $r_{i}\left[\mathrm{~kg} /\left(\mathrm{m}^{3} \mathrm{~s}\right)\right]$ was found:

$$
r_{i}=f_{0, i} \rho_{0} \frac{d X_{i}}{d t}
$$

where $f_{0, i}$ is the initial mass fraction of volatile component $i$ in the green anode. $\rho_{0}$ is the density of the green anode.

At present, no effort has been made to model volatile transport in the anode and packing coke bed. In a simple approach, the volatile generation rate in the $x z$-plane through the anodes is spatially integrated along the $y$-direction. This integrated generation rate is directly transferred to the corresponding part of the vertical flues of the pit for immediate combustion. It is difficult to estimate the modeling error introduced via this approximation.

\section{Heat transfer between gas and solids}

Since the temperature range of the combustion gases is between $100^{\circ} \mathrm{C}$ and $1300^{\circ} \mathrm{C}$, both convective and radiative heat transfer play a role. At low temperatures, the convective heat transfer mode is the most dominant one. However, at temperatures above $500^{\circ} \mathrm{C}$, radiation becomes important and in fact dominates at high temperatures.

$$
q^{\prime \prime}=q_{c}^{\prime \prime}+q_{r}^{\prime \prime}
$$

where $q^{\prime \prime}, q_{c}^{\prime \prime}$ and $q_{r}^{\prime \prime}$ are total, convective, and radiative heat flux respectively with unit $\mathrm{W} / \mathrm{mII}^{2}$. 


\subsection{Convective heat transfer}

Convective heat transfer is calculated from

$$
q_{c}^{\prime \prime}=h_{c}\left(T_{g}-T_{s}\right)
$$

where $q_{c}^{\prime \prime}$ is the convective heat flux from gas to solid material.

Along the gas path, the Reynolds number for the gas flow is in the order of $10^{4}$ which shows that forced convection takes place in the turbulent regime. Convective heat transfer coefficients were calculated from correlations for the Nusselt number:

$$
N u=\frac{h_{c} D_{h}}{k_{g}}
$$

$h_{c}$ is the convective heat transfer coefficient, $D_{h}$ is the hydraulic diameter of the gas-duct and $k_{g}$ is the gas thermal conductivity. A correlation attributed to Pethukov et al. was used for the Nusselt number (Incopeira and DeWitt 1990, p. 457):

$$
N u=\frac{\frac{f}{8} \operatorname{Re} \operatorname{Pr}}{1.07+12.7 \sqrt{\left(\frac{f}{8}\right)\left(\operatorname{Pr}^{2 / 3}-1\right)}}
$$

valid for

$$
\begin{aligned}
& 0.5<\operatorname{Pr}<2000 \\
& 10^{4}<\operatorname{Re}<5 \cdot 10^{6}
\end{aligned}
$$

Re is the Reynolds number, Pr denotes the Prandtl number. $f$ denotes the Moody friction factor. The correlation is widely used for turbulent flow. Heat transfer coefficients were calculated from mean values of the gas properties.

For the external lid surface, an appropriate correlation for the Nusselt number for laminar free convection was used.

\subsection{Radiative heat transfer}

\subsubsection{Radiative properties}

We use total hemispherical radiation properties in the model. Refractory surfaces are assumed gray so that absorptivity $\alpha_{s}$ equals emissivity $\epsilon_{s}$. The surfaces are opaque which means that transmittivity $\tau_{s}=0$. The surfaces are assumed to have diffuse radiation properties so that the reflected energy has equal intensity over all angles. For the total radiative properties we have $\alpha_{s}+\rho_{s}+\tau_{s}=1$. Since

$$
\alpha_{s}=\epsilon_{s}
$$

we get:

$$
\rho_{s}=1-\epsilon_{s}
$$

where $\rho_{s}$ denotes surface reflectivity. The combustion gas is assumed gray and nonreflective. For the gas radiative properties, we have

$$
\begin{aligned}
\alpha_{g} & =\epsilon_{g} \\
\tau_{g} & =1-\epsilon_{g}
\end{aligned}
$$

since $\rho_{g}=0$. 
Plate 1

\section{Plate 2}

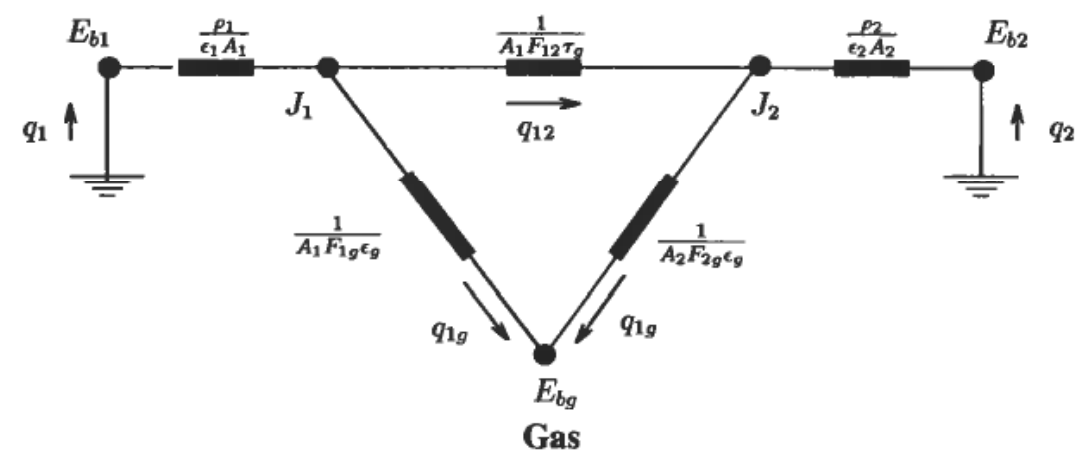

Figure 10. Radiation diagram for two finite plates with intermediate combustion gas as a refractory surface. From Kreith and Black (1980).

\subsubsection{Radiative heat flux calculation}

For the flue channels and headwall it can be shown that the radiative heat flux $q_{r, g s}^{\prime \prime}$ $\left(\mathrm{W} / \mathrm{m}^{2}\right)$ from gas to surface $A_{s}\left(\mathrm{~m}^{2}\right)$ is given by:

$$
q_{r, g s}^{\prime \prime}=\frac{q_{g s}}{A_{s}}=\sigma \mathscr{F}_{g s}\left(T_{g}^{4}-T_{s}^{4}\right)
$$

where

$$
\mathscr{F}_{g s}=\frac{1}{\frac{1}{\epsilon_{g}}+\frac{1}{\epsilon_{s}}-1}
$$

$T_{g}$ and $T_{s}$ denote average gas and surface temperatures respectively. $\mathscr{F}_{g s}$ is the radiative factor between gas and surface, $\epsilon_{g}$ is the gas emissivity, and $\epsilon_{s}$ is the surface emissivity. The expression for radiative heat transfer under-lid and under-pit are given by more complicated expressions. For the under-pit area, we used a thermal circuit as shown in Fig. 10 for two finite plates, and combustion gas as a refractory surface. Analytical expressions (calculations were executed in Mathematica ${ }^{\mathrm{TM}}$ ), for the net radiation heat fluxes were obtained by simplification of the thermal circuit assuming the plates to have equal surface areas $A$ and emissivities $\boldsymbol{\epsilon}_{\boldsymbol{s}}$.

$$
\begin{aligned}
& q_{r, g}^{\prime \prime}=\sigma \mathscr{F}_{g}\left(T_{1}^{4}-T_{g}^{4}\right)+\sigma \mathscr{F}_{g}\left(T_{2}^{4}-T_{g}^{4}\right) \\
& q_{r, 1}^{\prime \prime}=\sigma \mathscr{F}_{g}\left(T_{1}^{4}-T_{g}^{4}\right)+\sigma \mathscr{F}_{12}\left(T_{1}^{4}-T_{2}^{4}\right)
\end{aligned}
$$

where

$$
\begin{aligned}
\mathscr{F}_{g s} & =\frac{1}{\frac{1}{\epsilon_{g}}+\frac{1}{\epsilon_{s}}-1} \\
\mathscr{F}_{12} & =\frac{\epsilon_{s}^{2}\left(1-\epsilon_{g}\right)}{\left[\epsilon_{s}+\epsilon_{g}\left(1-\epsilon_{s}\right)\right]\left[1+\left(1-\epsilon_{g}\right)\left(1-\epsilon_{s}\right)\right]}
\end{aligned}
$$

$q_{r, g}^{\prime \prime}$ is net radiated heat flux from gas to plates. $q_{r, 1}^{\prime \prime}$ is net radiated heat flux from plate 1. $T_{1}$ and $T_{2}$ denote average surface temperatures.

For the under-lid combustion chamber, the surfaces have different areas and 
emissivities. Therefore, slightly more complicated expressions for the radiation heat fluxes (not reported here) were obtained even though the same thermal circuit was used as basis.

For the lid outer surface, air emissivity and absorptivity were neglected and the radiative heat flux calculated from

$$
q_{r}^{\prime \prime}=\sigma \epsilon_{\mathrm{lid}}\left(T_{\mathrm{lid}}^{4}-T_{a}^{4}\right)
$$

where $T_{a}$ is the average temperature of roof, walls etc. in the furnace hall. The expression is valid for a small convex object dwelling in a large cavity.

\section{Modeling of gas phenomena}

Along the gas path, submodels based on the heat balance in (1) were derived for each zone described in section 2. Except for the under-lid zone, plug flow was assumed for the gas flow. In the headwall in part $A$, fuel is sprayed into the main gas flow via vertically positioned burners. In the vertical flues, pitch volatiles enter via cracks and joints in the brickwork. In summary, the other assumptions are as follows:

(1) A stationary gas model was used.

(2) Fuel combustion was assumed to complete in the headwall and under-lid regions.

(3) Uniform temperature (ideal mixing) was assumed for the gas in the under-lid region.

(4) Volatile combustion was assumed complete in the vertical flues.

(5) There is no model for air inleakage. Air infiltration was taken care of by adjusting gas flow at section inlet.

(6) Gas flows typically occur at high Peclet numbers $\mathrm{Pe}=\rho v d / D$. Pe is the ratio between strength of convection and diffusion (Patankar 1980). Here Pe $\gg 1$ and convection dominates compared to the dispersion (diffusion) terms represented by dispersion coefficient $D$. Dispersion is thus omitted from the equations.

(7) The mass flow distribution in the vertical flue channels is known from velocity field calculations performed in the commercial fluid flow package FLUENT (also verified experimentally). Based on these results a certain mass flow distribution was assumed.

Since the mass flow distribution along the gas path is known a priori, calculation of impulse balances (Navier-Stokes equation) does not have to be performed. This greatly simplifies the simulations. Mass flow and temperature along the gas path can be found from coupled mass and energy balances. To obtain these balances, idealized model concepts were used for the calculation zones along the gas path. In the under-lid compartment, ideal mixing and uniform gas temperature is assumed. Plug flow of gas was assumed to occur in the other gas compartments. However, the under-pit region has side flows of gas from the vertical flues leaving or entering the zone in part $A$ and $B$ respectively. From the under-pit zone in part $A$, gas enters the vertical flues in the pit-wall belonging to part $A$. Gases from the under-lid region enters the vertical flues in part $B$ and finally exit into the under-pit region of part $B$.

In the combustion zones, gas compartment mass balances are updated to obtain corrected values for the gas properties discussed in Subsection 5.3. 


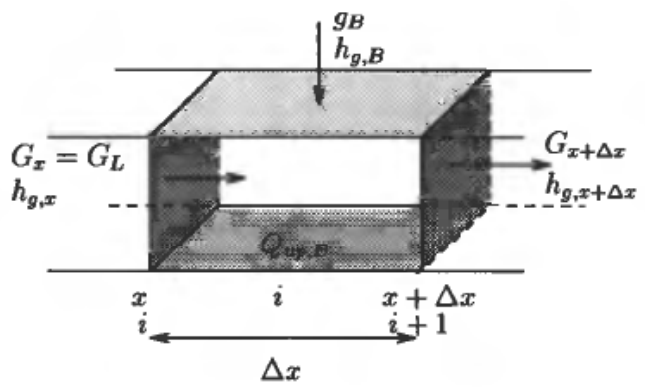

Figure 11. Typical under-pit gas computational cell. Note indexing of boundary control volume surfaces. Boundary surfaces in control volumes both along gas path and in the solid materials are indexed in this way (see also Fig. 12).

\subsection{Example of mass and energy balance for the gas}

To illustrate the modeling procedure, we derive mass- and energy balances for the under-pit zone in part $B$. The main gas flow is in the $x$-direction of the furnace with side flows from the vertical flues. As mentioned above, the flue channel mass flow distribution is known from calculations and experiments.

The mass balance is given by

$$
\frac{\partial \rho_{g}}{\partial t}=-\frac{\partial\left(\rho_{g} v\right)}{\partial x}+\frac{1}{A_{g}} g_{B}
$$

which gives

$$
\frac{\partial G}{\partial x}=g_{B}
$$

for the stationary mass balance. $G=\rho_{g} v A_{g}(\mathrm{~kg} / \mathrm{s})$ denotes mass flow where $\rho_{g}$ is gas density, $v$ is gas velocity, and $A_{g}$ is the cross section of the gas flow. $A_{g}$ has different values for each zone along the gas path. $g_{B}(\mathrm{~kg} / \mathrm{ms})$ is mass flow per unit length in $x$-direction which comes from the vertical flue channels. $g_{B}$ is positive for gas flow entering the control volume.

For the energy balance, we get:

$$
\frac{\partial\left(\rho_{g} u_{g}\right)}{\partial t}=\frac{\partial\left(\rho_{g} v h_{g}\right)}{\partial x}+\frac{\partial\left(\rho_{g} v\right)}{\partial x} h_{g, B}+\frac{1}{A_{g}} Q_{u p, B}
$$

Using mass flow $G=\rho_{g} u_{g} A_{g}$, we get:

$$
-\frac{\partial\left(G h_{g}\right)}{\partial x}+\frac{\partial G}{\partial x} h_{g, B}+Q_{u p, B}=0
$$

for the stationary heat balance. $u_{g}$ is the specific internal energy of the gas, $h_{g}(\mathrm{~J} / \mathrm{kg})$ is specific enthalpy of the gas flow, and $h_{g, B}$ is specific enthalpy (for an ideal gas, $h_{g}=u_{g}+p\left(1 / \rho_{g}\right)$ where $p$ is the gas pressure), of inflowing gas from the vertical flue channels. $Q_{u p, B}(\mathrm{~W} / \mathrm{m})$ is heat transfer (conductive and radiative) from refractory brickwork to gas per unit length of the furnace in the under-pit region of part $B$.

\subsection{Summary of gas path equations}

A summary of dynamic mass- and energy balances along the gas path is given 
below. Stationary versions of the equations, as shown in subsection 5.1 were used in the simulations. In the list of equations, the mass balance appears first for each gas compartment.

(1) Headwall:

$$
\begin{aligned}
\frac{\partial \rho_{g}}{\partial t} & =-\frac{\partial\left(\rho_{g} v\right)}{\partial x}+\frac{1}{A_{g}} g_{f} \\
\frac{\partial\left(\rho_{g} u_{g}\right)}{\partial t} & =-\frac{\partial\left(\rho_{g} v h_{g}\right)}{\partial x}+\frac{1}{A_{g}} g_{f} \Delta H_{f}+\frac{1}{A_{g}} Q_{h d w}
\end{aligned}
$$

$g_{f}(\mathrm{~kg} / \mathrm{ms})$ is the fuel flow per unit length (in the direction of gas flow) entering the headwall normal to the main gas flow. $\Delta H_{f}(\mathrm{~J} / \mathrm{kg})$ is the fuel oil combustion enthalpy.

(2) Under-pit in part A:

$$
\begin{gathered}
\frac{\partial \rho_{g}}{\partial t}=-\frac{\partial\left(\rho_{g} v\right)}{\partial x}+\frac{1}{A_{g}} g_{A} \\
\frac{\partial\left(\rho_{g} u_{g}\right)}{\partial t}=-\frac{\partial\left(\rho_{g} v h_{g}\right)}{\partial x}+\frac{\partial\left(\rho_{g} v\right)}{\partial x} h_{g}+\frac{1}{A_{g}} Q_{u p, A}
\end{gathered}
$$

$g_{A}(\mathrm{~kg} / \mathrm{ms})$ is the mass flow per unit length of furnace (in the direction of gas flow) entering the vertical flues in part $A . g_{A}$ is negative for gas exiting the under pit zone.

(3) Vertical flue channels in part A:

$$
\begin{aligned}
\frac{\partial \rho_{g}}{\partial t} & =-\frac{\partial\left(\rho_{g} v\right)}{\partial z}+\frac{1}{A_{g}} \sum_{i=1}^{n_{v}} g_{v, i} \\
\frac{\partial \rho_{g} u_{g}}{\partial t} & =-\frac{\partial\left(\rho_{g} v h_{g}\right)}{\partial z}+\frac{1}{A_{g}} \sum_{i=1}^{n_{v}} g_{v, i} \Delta H_{v, i}+\frac{1}{A_{g}} Q_{c h n, A}
\end{aligned}
$$

$g_{v, i}(\mathrm{~kg} / \mathrm{ms})$ is the volatile mass flow per length of flue channel. $\Delta H_{v, i}(\mathrm{~J} / \mathrm{kg})$ is the combustion enthalpy of the volatile gases. $Q_{c h n, A}(\mathrm{~W} / \mathrm{m})$ is the heat transfer per length of flue channel.

(4) Under-lid:

$$
\begin{gathered}
\frac{d\left(\rho_{g} V_{\text {ulid }}\right)}{d t}=\sum_{i=1}^{n_{\text {chn }, A}} G_{A, i}-G+G_{f} \\
\frac{d\left(\rho_{g} V_{\text {ulid }} u_{g}\right)}{d t}=\sum_{i=1}^{n_{c h n, A} A} G_{A, i} h_{A, i}-G h+G_{f} \Delta H_{f}
\end{gathered}
$$

$G_{A, i}=\rho_{g} v_{A, i} A_{g}$ is the mass flows from the vertical flue channels in part $A$ which enter the under-lid zone. $v_{A, i}$ is the flue channel exit velocity. Here $A_{g}$ denotes the cross section of the flue channels in part $A$.

(5) Vertical flue channels in part $B$ :

$$
\begin{aligned}
\frac{\partial \rho_{g}}{\partial t} & =-\frac{\partial\left(\rho_{g} v\right)}{\partial z}+\frac{1}{A_{g}} \sum_{i=1}^{n_{v}} g_{v, i} \\
\frac{\partial\left(\rho_{g} u_{g}\right)}{\partial t} & =-\frac{\partial\left(\rho_{g} v h_{g}\right)}{\partial z}+\frac{1}{A_{g}} \sum_{i=1}^{n_{v}} g_{v, i} \Delta H_{v, i}+\frac{1}{A_{g}} Q_{c h n, B}
\end{aligned}
$$


(6) Under-pit part B:

$$
\begin{aligned}
\frac{\partial \rho_{g}}{\partial t} & =-\frac{\partial\left(\rho_{g} v\right)}{\partial x}+\frac{1}{A_{g}} g_{B} \\
\frac{\partial\left(\rho_{g} u_{g}\right)}{\partial t} & =-\frac{\partial\left(\rho_{g} v h_{g}\right)}{\partial x}+\frac{\partial\left(\rho_{g} v\right)}{\partial x} h_{g, B}+\frac{1}{A_{g}} Q_{u p, B}
\end{aligned}
$$

$g_{B}(\mathrm{~kg} / \mathrm{ms})$ is the gas flow per unit length (in direction of gas flow) entering the under-pit zone from the vertical flues in part $B$.

The equations for the under pit zone in part $B$ are repeated for convenience. Details on boundary conditions for the above equations are not given.

\subsection{Gas properties}

For heat transfer calculations, the following combustion gas properties were needed:

(1) Density: $\rho_{g}$

(2) Specific heat capacity: $c_{p, g}$

(3) Thermal conductivity: $k_{g}$

(4) Viscosity: $\mu_{g}$

(5) Emissivity: $\epsilon_{g}$

Mean gas properties were calculated from knowledge of the gas composition. Fractions of nitrogen $\mathrm{N}_{2}$, oxygen $\mathrm{O}_{2}$, carbon dioxide $\mathrm{CO}_{2}$ and water vapour $\mathrm{H}_{2} \mathrm{O}(\mathrm{g})$ were considered since the combustion calculations were based on instantaneous and ideal combustion as discussed in Subsection 5.4. The combustion gas density is given by:

$$
\rho_{g}=\frac{p M}{R T}
$$

where $M$ is the average molar mass of the gas mixture:

$$
M=\sum_{i=1}^{n} \frac{1}{y_{i} / M_{i}}
$$

where $y_{j}$ is component mass fraction, and $n$ is the number of gas components considered. Specific heat capacity is calculated as a weighted average:

$$
c_{p}=\sum_{j=1}^{n} y_{j} c_{p, g, j}
$$

Correlations for gas component heat capacities were taken from (Reid, Praunitz and Poling 1988).

Gas mixture thermal conductivity and viscosity were calculated from the Wassiljewa equation (Mason and Saxena modification) and Wilke correlation respectively (Reid et al. 1988, pp. 530, 531 and 407).

$$
\begin{aligned}
& k_{g}=\sum_{i=1}^{n} \frac{y_{i} k_{i}}{\sum_{j=1}^{n} j_{j} \phi_{i j}} \\
& \mu_{g}=\sum_{i=1}^{n} \frac{y_{i} \mu_{i}}{\sum_{j=1}^{n} y_{j} \phi_{i j}}
\end{aligned}
$$




$$
\phi_{i j}=\frac{\left[1+\left(\frac{\mu_{i}}{\mu_{j}}\right)^{1 / 2}\left(\frac{M_{j}}{M_{i}}\right)^{1 / 4}\right]^{2}}{\left[8\left(1+\frac{M_{i}}{M_{i}}\right)\right]^{1 / 2}}
$$

Component thermal conductivities and viscosities were obtained from Reid et al. (1988, Tab. 10-3, pp. 515-516) and Lydersen (1983, App. 5, p. 314).

For calculation of mean gas emissivity, emissivities of $\mathrm{CO}_{2}$ and $\mathrm{H}_{2} \mathrm{O}$ were considered since they are among the most important nonsymmetrical gases for radiative emission. Diagrams for $\epsilon_{\mathrm{H}_{2} \mathrm{O}}$ and $\epsilon_{\mathrm{CO}_{2}}$ as function of temperature, partial pressure and mean beam length were found in Kreith and Black (1980, pp. 353-354). The gas mixture emissivity was calculated from:

$$
\epsilon_{g}=\epsilon_{\mathrm{H}_{2} \mathrm{O}}+\epsilon_{\mathrm{CO}_{2}}-\Delta \epsilon
$$

at a total pressure of 1 bar. $\Delta \epsilon$ accounts for the overlapping radiative wavelength bands for $\mathrm{H}_{2} \mathrm{O}$ and $\mathrm{CO}_{2}$. The correction term $\Delta \epsilon$ was set to zero.

The gas emissivity calculated by the above expression is not valid in the flame zone. For luminous flames, emissivity data should be derived from experiments with flames similar to that of interest. In this case, experimental results were not available. But since flame radiative heat transfer is based on a mean flame temperature, emissivity was calculated by adding $\mathbf{0 . 1}$ to the nonluminous gas emissivity to include luminous soot emissivity in the flame zone (Perry and Green 1984, pp. 10-63).

\subsection{Ring furnace combustion processes}

As a first approach, complete combustion was assumed. For complete stochiometric oxidation of a hydrocarbon $\mathrm{C}_{m} \mathrm{H}_{n}$, the following relationship holds

$$
\mathrm{C}_{m} \mathrm{H}_{n}+\left(m+\frac{n}{4}\right) \mathrm{O}_{2} \rightarrow m \mathrm{CO}_{2}+\frac{n}{2} \mathrm{H}_{2} \mathrm{O}
$$

Using this equation, mass balances along the gas path for the combustion gas components were calculated.

As mentioned before, packing coke combustion was not included, since this phenomenon mainly occurs during anode cooling.

It was assumed that a fuel oil with approximate stochiometric formula $\left(\mathrm{C}: \mathrm{H} \approx 87: 13\right.$ by mass), $\mathrm{CH}_{1 \cdot 8}$ and a lower heating value of $42000 \mathrm{~kJ} / \mathrm{kg}$ was representative for typical oils used for operating the furnace.

Dernedde $\boldsymbol{e t}$ al. have studied the kinetics of volatile combustion (Dernedde $\mathrm{et}$ al. 1986). The maximum evolution rates for methane and hydrogen occur at temperatures above gas ignition temperature. Therefore, we assume that $\mathrm{CH}_{4}$ and $\mathrm{H}_{2}$ combustion rates equal the evolution rate from the carbon blocks, since volatile diffusion through the anode and packing coke was neglected. As a preliminary approach, complete combustion was also assumed for the tar fraction. Volatile combustion was assumed to take place in the vertical flues due to injection of pitch volatiles through cracks and joints in the brickwork.

\section{Numerical schemes}

The control-volume formulation described in Patankar (1980) was used to obtain discretized heat conduction equations. In this discretization method, the partial differential equation is integrated over each control volume which implies property conservation at control volume level. 


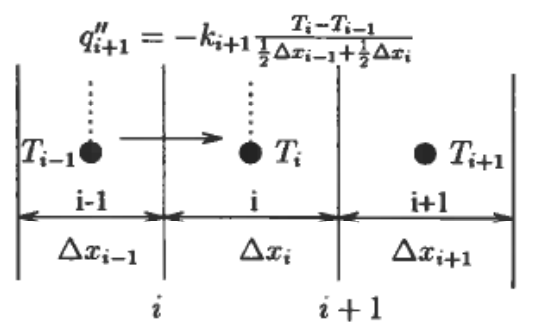

Figure 12. Control volume in a one-dimensional grid. Note indexing of boundary control volume surfaces. Boundary surfaces in control volumes both along gas path and in the solid materials are indexed in this way (see also Fig. 11).

The grid was designed with control volume faces located midway between grid points. At surfaces with discontinuity in material properties, the grid was chosen so that control volume faces and discontinuity surfaces coincide. For simplicity, a uniform grid was used within each type of material.

\subsection{Heat conduction equations}

The discretization procedure can be illustrated by an example for a one dimensional heat conduction problem. Integrating the one dimensional heat equation over the control volume shown in Fig. 12, gives

$$
\rho_{i} c_{p i} \frac{\partial T_{i}}{\partial t} \Delta x_{i}=\left.k \frac{\partial T}{\partial x}\right|_{i+1}-\left.k \frac{\partial T}{\partial x}\right|_{i}
$$

$i+1$ and $i$ denote right- and left hand side control volume faces for grid point $i$. We assume a linear temperature profile between the grid points so that

$$
\begin{aligned}
\left.\frac{\partial T}{\partial x}\right|_{i+1} & =\frac{T_{i+1}-T_{i}}{\frac{1}{2} \Delta x_{i+1}+\frac{1}{2} \Delta x_{i}} \\
\left.\frac{\partial T}{\partial x}\right|_{i} & =\frac{T_{i}-T_{i-1}}{\frac{1}{2} \Delta x_{i}+\frac{1}{2} \Delta x_{i-1}}
\end{aligned}
$$

By insertion of these expressions in (51), we obtain an ordinary differential equation for the temperature at the $i$ th grid point:

$$
\rho_{i} c_{p i} \frac{d T_{i}}{d t}=2 k_{i+1} \frac{T_{i+1}-T_{i}}{\Delta x_{i}\left(\Delta x_{i}+\Delta x_{i+1}\right)}-2 k_{i} \frac{T_{i}-T_{i-1}}{\Delta x_{i}\left(\Delta x_{i-1}+\Delta x_{i}\right)}
$$

For the left- and right hand side interface conductivities $k_{i}$ and $k_{i+1}$, we have:

$$
\begin{gathered}
k_{i}=\left[\frac{\frac{\Delta x_{i-1}}{\Delta x_{i-1}+\Delta x_{i}}}{k_{i-1}}+\frac{\Delta x_{i}}{\frac{\Delta x_{i-1}+\Delta x_{i}}{k_{i}}}\right]^{-1} \\
k_{i+1}=\left[\frac{\frac{\Delta x_{i}}{\Delta x_{i}+\Delta x_{i+1}}}{k_{i}}+\frac{\Delta x_{i+1}}{\frac{\Delta x_{i}+\Delta x_{i+1}}{k_{i+1}}}\right]^{-1}
\end{gathered}
$$

For the furnace lid, this one-dimensional model was used. The procedure described for the one-dimensional case was used along other coordinate axes to obtain discretized equations in two (foundation) and three (pit) dimensions too. 
The derived equation is valid only for internal grid points. For the boundary grid points, boundary conditions were applied according to specifications given in subsections 3.2 and 3.3.

\subsection{Gas equations}

The control volume method and upwind scheme described by Patankar (1980) was used to obtain discretization equations for the gas model. The numerical model equations derived from the gas equations in subsection 5.1 are reported here. Integration over the computational cell, gives

$$
G_{i+1}=G_{i}+g_{B} \Delta x
$$

for the mass balance. To obtain the discretization equation for the energy balance, we use:

$$
\frac{d h}{d T}=c_{p}
$$

for the gas enthalpy $h$ where $c_{p}$ is the gas specific heat capacity at constant pressure. The following discretization equation was derived for the under-pit zone in part $B$ by integration over the control volume

$$
T_{i}=\frac{G_{i}}{G_{i+1}} T_{i-1}+\frac{\left(G_{i+1}-G_{i}\right)}{G_{i+1}} T_{i n, i}+\frac{1}{G_{i+1} \bar{c}_{p, i}} Q_{i} \Delta x
$$

$G_{i}$ is mass flow across the left hand side control volume face as shown in Fig. 11. $\bar{c}_{p, i}$ is an average heat capacity dependent on $T_{i-1}, T_{i}$ and gas composition.

We see that in this model formulation, there is a one way coupling between the mass- and energy balances. Thus, the equations are conveniently solved in sequence: First solve the mass balance in the direction of flow. With a known value of $G_{i+1}$, we can solve the energy balance for $T_{i}$.

Similar model equations for the other gas compartments may be derived. For the flue channels and under-lid zone, enthalpies of volatiles and fuel must be included in the energy balances.

\section{Computational procedure}

Inlet conditions for a section were obtained by using nominal values for gas temperature and composition in the headwall. The most time consuming part of the algorithm was the calculation of the three dimensional temperature field in the pit. An explicit integration method was used for solving the heat conduction equations. The time step had to be chosen in the order of 100 seconds to assume stability to the numerical scheme. Initial values for the numerical solution were obtained as follows:

(1) Initial value solids: Room temperature $T=20^{\circ} \mathrm{C}$.

(2) Initial value gas: Solve gas equations for given input conditions in headwall and use the initial solid temperature field as boundary conditions.

The computations were performed as two main tasks at each time step:

(1) From specified refractory surface temperature and headwall gas input conditions: 
(a) Calculate boundary conditions for gas model equations.

(b) Solve the mass- and energy balance equations along the gas path in the direction of gas flow.

(2) From specified gas temperature and composition along the gas path:

(a) Calculate solid boundary conditions.

(b) Integrate the heat conduction equations using an explicit integration method and temperature varying properties.

Alternating between steps 1 and 2, simulations were performed over a time interval covering the preheat and heating periods of a fire cycle. The cooling period of the baking cycle was not simulated. For the under-lid zone, the amount of fuel necessary to maintain a predetermined temperature profile in time, was calculated.

In the present model implementation, solid and gas properties are updated at a certain number (which can be set by the user) of time steps. The temperature field is calculated by using the explicit Euler method with no time step control.

\section{Simulation results}

The baking behaviour during the preheating and heating parts of the fire-cycle was simulated. Gas flow input conditions (temperature and composition) were specified. Further, a time varying mass flow input profile is used to represent the increase in mass flow of gas due to air inleakage. A fire-step of $36 \mathrm{~h}$ was chosen and the model was simulated over a time interval of $180 \mathrm{~h}$ corresponding to 5 fire-steps. The under-lid fuel consumption needed for maintaining the under-lid temperature tracking a certain trajectory, was calculated (see Fig. 13). The desired temperature trajectories (normalized values) in headwall and under-lid are shown in Fig. 14.

In the numerical model, the grid resolution can be specified by the user. In the results presented, a fine mesh was used with approximately 6000 grid points in the solid materials of pit refractory, coke, and anode. Correspondingly, along the gas path there were in the order of 500 grid points. One computing cycle takes approximately one $h$ on a Sparc Work Station. Data from the simulations are stored on a Matlab-readable format. Postprocessing and graphical presentation are done in Matlab.

In Fig. 15, the time history of the (normalized) temperature in the $x z$-plane through the anode centre is shown. Early in the baking cycle, we see that the hottest parts of the anodes face the brickwork foundation in the pit. This tendency is maintained up to baking times of approximately $130 \mathrm{~h}$. Then the effect of the under-lid burner now operative for approximately $50 \mathrm{~h}$ becomes visible: the temperature field becomes more uniform. After $180 \mathrm{~h}$, the highest temperatures occurs on the top surface of the anodes in part $B$ of the pit. The lowest temperature in the anode centre was detected in part $A$ (close to the headwall) of the pit. Even though the burner in part $A$ is operated by vertical firing through a fire-shaft in the headwall, there is loss of heat through the headwall. The coldest position occurs in the headwall region of part $A$. The temperature profile has a saddle-like shape, and it can be concluded that the profile is very sensitive to the headwall boundary condition.

The temperature field's sensitivity to an alternative headwall boundary condition was tested. The simulation were repeated with an adiabatic boundary condition specified for the whole headwall. The temperature difference (original vs. new headwall 


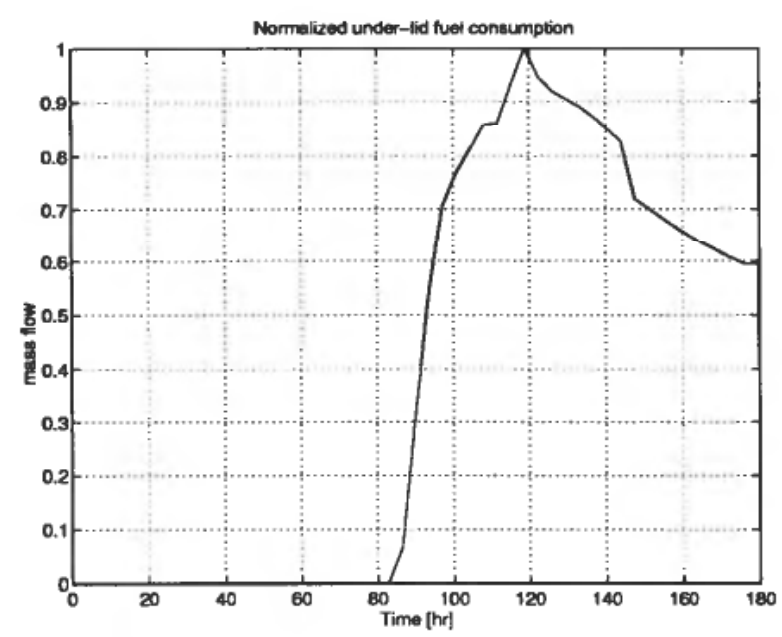

Figure 13. Normalized under-lid fuel mass flow. The burner is switched on after approximately $80 \mathrm{~h}$ of baking, since gas temperature has to reach a certain level before ignition can occur.

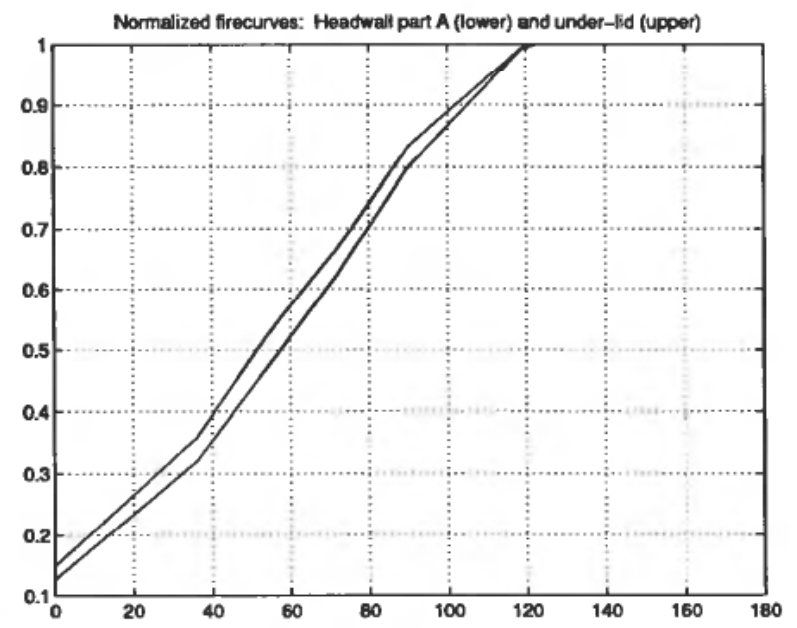

Figure 14. Normalized fire curves for ring furnace operation. In traditional ring furnace operation, tracking along these curves is implemented either via manual or automatic control.

boundary condition) in the $x z$-plane through the anode centre is shown in Fig. 16. We see that the adiabatic headwall boundary condition causes an even lower temperature in the anode in regions facing the headwall than obtained with the original boundary condition. The effect is most marked in the part $B$ region of the pit.

The difference between anode surface temperature $(7 \mathrm{~cm}$ below anode surface) in the $x z$-plane and anode centre temperature ( $x z$-plane) is shown in Fig. 17. Up to 60h of baking, the highest gradients ( $x z$-plane) occur in part $A$. After $90 \mathrm{~h}$ of baking, the largest gradients are found in part $B$. After $180 \mathrm{~h}$ of baking, the minimum temperature difference is found at the top of the anodes in part $A$. The maximum temperature difference is found in the bottom of part $B$. 

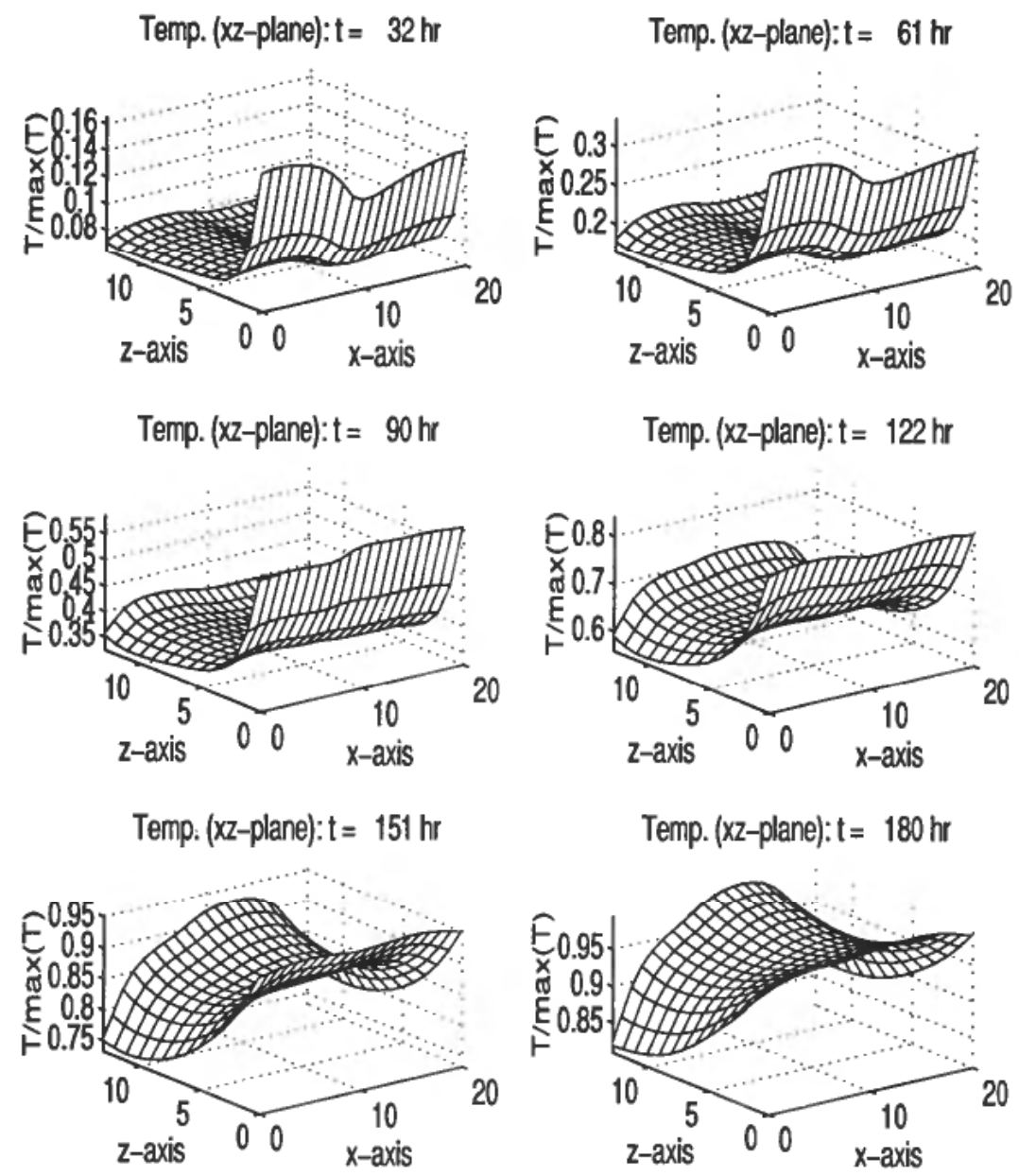

Figure 15. History of temperature in centre of anodes (xz-plane) after 180h. Data are normalized such that maximum value 1 corresponds to the maximum temperature of the anodes during the whole baking cycle. Axes denote grid point in $x$ - and $z$-directions. To be able to show the details in the temperature profiles, the interval along the temperature axis varies between the different panels.

The typical lag between gas-, and anode surface- and anode-centre (normalized) temperatures is shown in Fig. 18. We see that there is a significant lag between gas and solid temperatures. It may be inferred that design of ring furnace baking strategies is not a straightforward task. To arrive at anodes with uniform properties, care must be taken during critical parts of the baking process.

Finally, some plots of volatile generation (source terms) based on the thermogravimetric model are presented. In Fig. 19, a maximum of $4.3\left(\mathrm{~kg} / \mathrm{m}^{3} \mathrm{~s}\right) \mathrm{tar}$ volatiles is released from a certain position in the $x z$-plane through the centre of the anodes. A typical snap-shot of the tar volatile generation (after $94 \mathrm{~h}$ of baking) is seen in Fig. 20. In parts of the anode facing brickwork and top coke layer, volatile generation has ceased. Also in parts $A$ and $B$ volatile generation is about to cease. Note that the generation rate in the cold parts neighbouring the headwall areas has a certain lag compared to the generation rates observed in the central part of the centre $x z$-plane. 

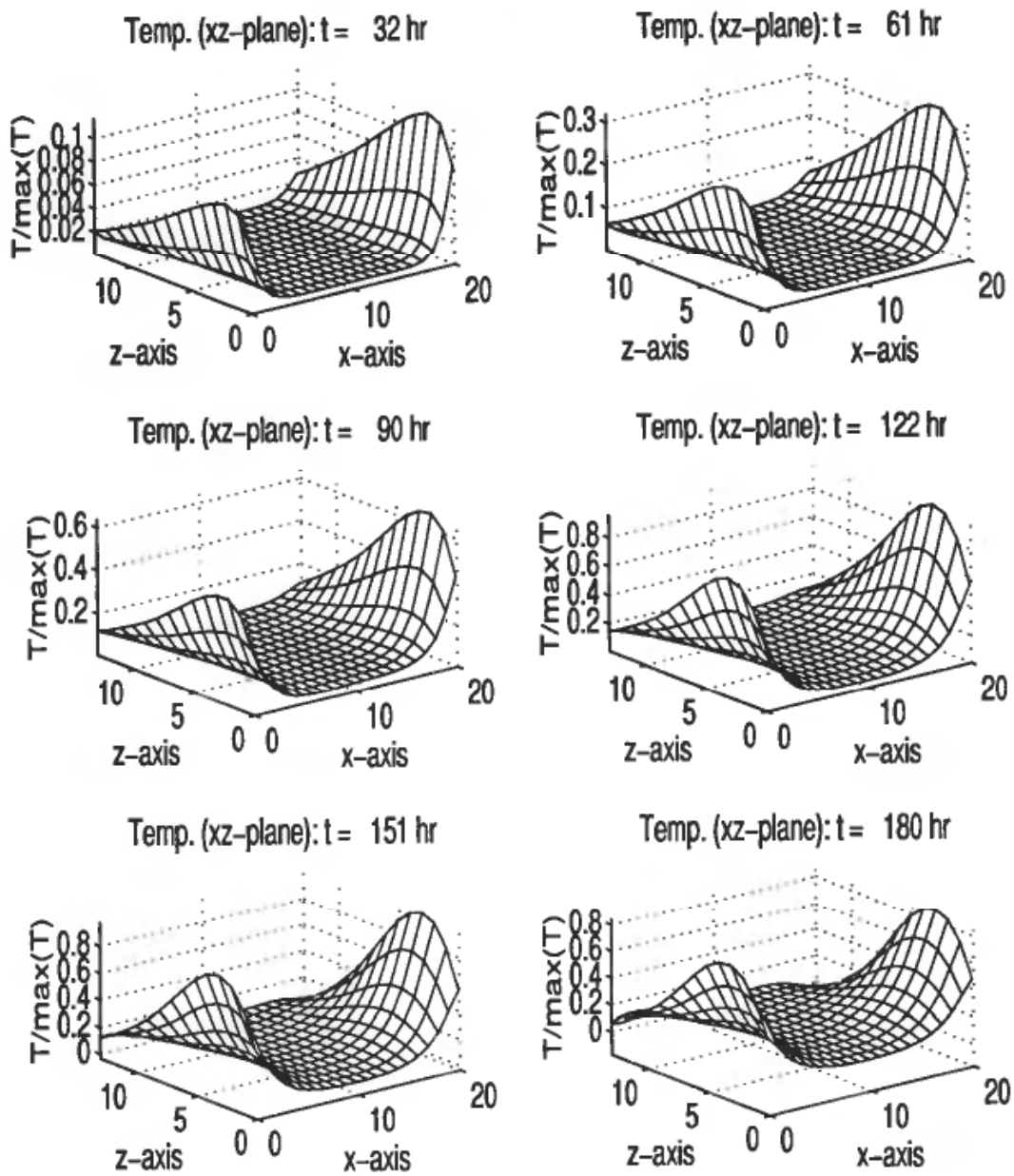

Figure 16. Comparison of headwall boundary conditions: original fireshaft boundary conditions against adiabatic headwall boundary conditions. The data are normalized according to the maximum difference occurring. The interval along the normalized temperature axis changes from panel to panel.

\section{Conclusions}

Calculation of temperature profiles in ring furnaces have been conducted for several years. In this article, a model for the heat balance in a Hydro Aluminium ring furnace is presented. This kind of ring furnaces have a modified gas path compared to the conventional closed furnaces and thus allows for a better heat distribution along the flues.

In the model presented, the basic ring furnace phenomena are included. Focus is put on calculation of the heat balance for the furnace. To arrive at a model with a reasonable complexity, a lot of simplifications were necessary and the effect of these simplifications can only be tested by comparison of experimental data with simulations. At present, no systematic comparison of the model and experimental data has yet been performed, but the observations are comparable to measurements done on a real furnace of Hydro Aluminium type. However, the model gives a qualitatively correct description of basic ring furnace operation.

Large model-uncertainties occur in the thermal properties of the anodes. In this 

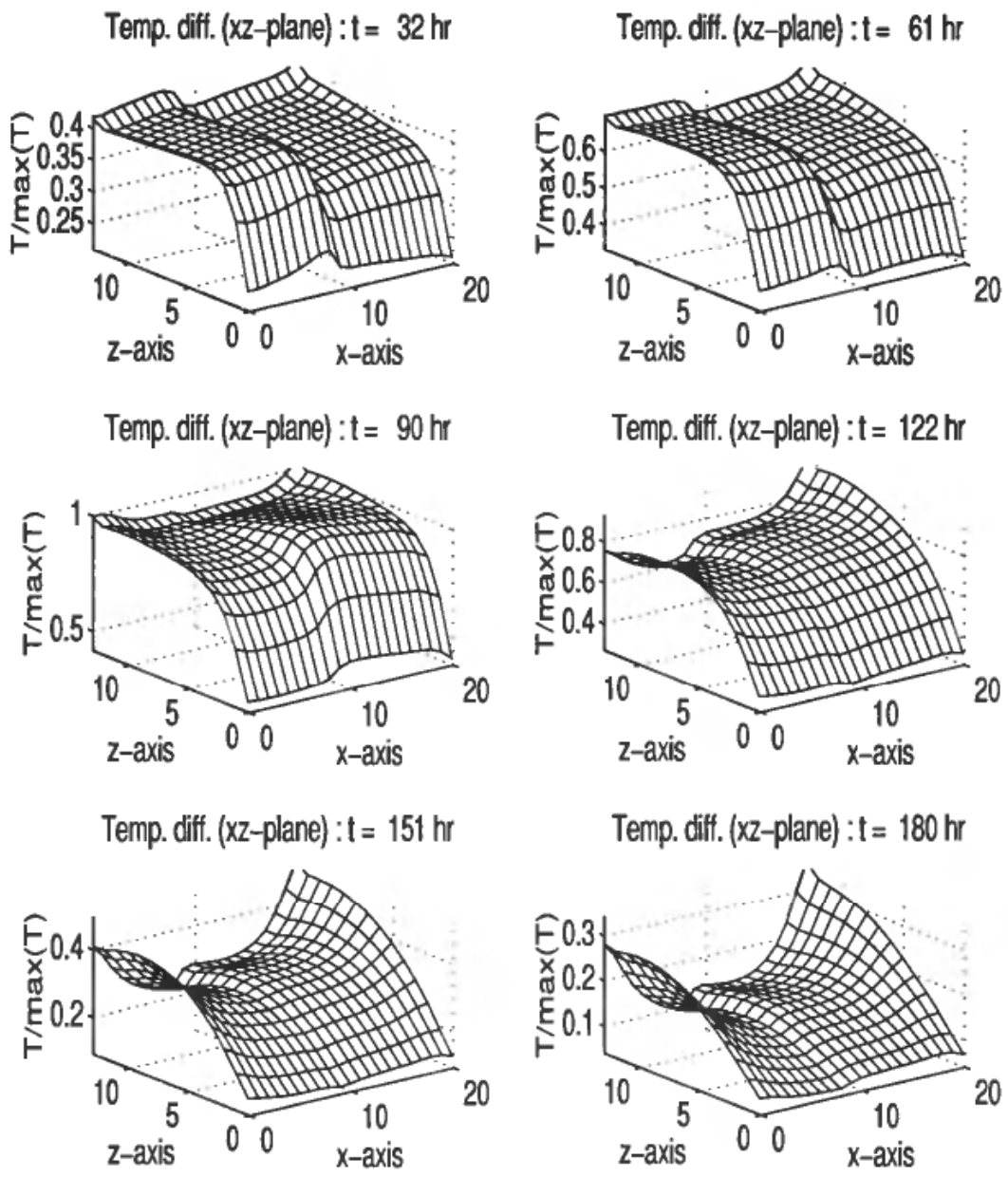

Figure 17. Normalized temperature difference in $x z$-plane between anode surface $(7 \mathrm{~cm}$ below anode surface) and anode centre. Maximum difference is found in part $B$. Temperature is normalized such that maximum value 1 corresponds to the maximum temperature difference occurring during the baking cycle.

model, the properties are given as functions of temperature. A more realistic model would take into account the influence of baking conditions (heating rate, spatial gradients) on these properties. There is a lack of data in the literature, and not much work has been done in dynamical modeling of such properties.

Also in modeling of gas flow through the headwall-, under-lid and under-pit zones there is a significant degree of uncertainty. The heat transfer coefficients and effective emissivity are difficult to obtain since there is a complex relationship between duct geometry and flame profile in these zones. However, the approach to modeling of those parameters is in accordance with state of the art in heat transfer calculations.

A lot of parameters are needed in the model and the modeling of boundary conditions for the pit heat conduction problem is not straightforward. Two different headwall boundary conditions were tested and it was shown that the model is sensitive to the boundary conditions used. A lot of work remains in the study of model sensitivity to parameter variations.

The equations for the subsystems gas and solids were solved by using a stationary 


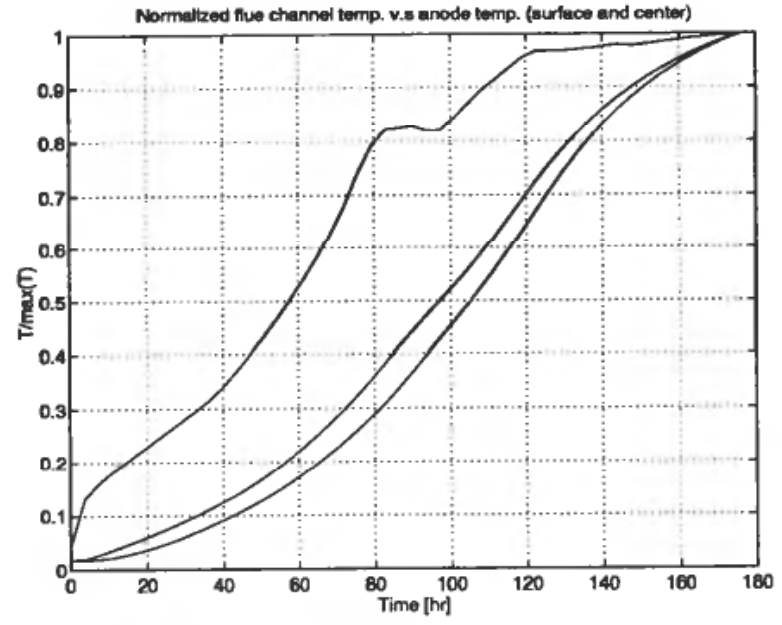

Figure 18. Typical lag between normalized temperatures in gas and anode (surface and centre).

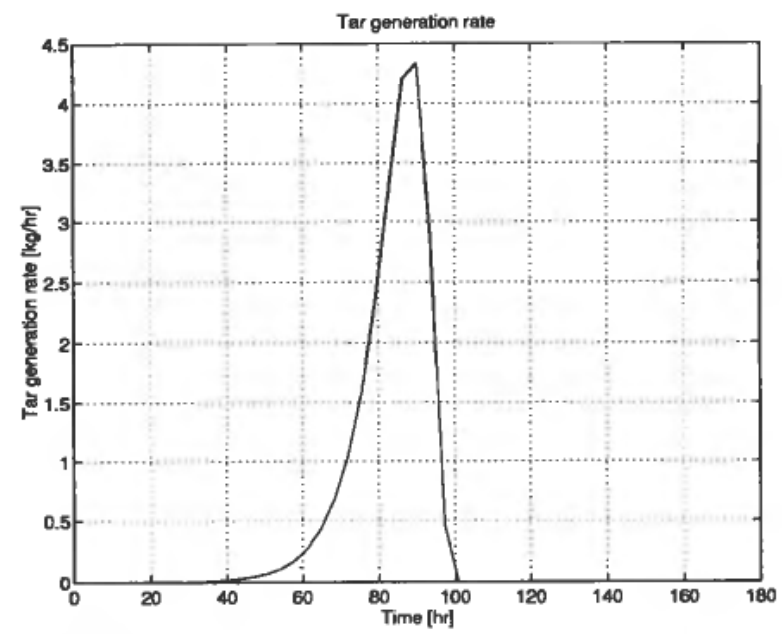

Figure 19. Typical tar volatile generation rate in the anodes as function of time.

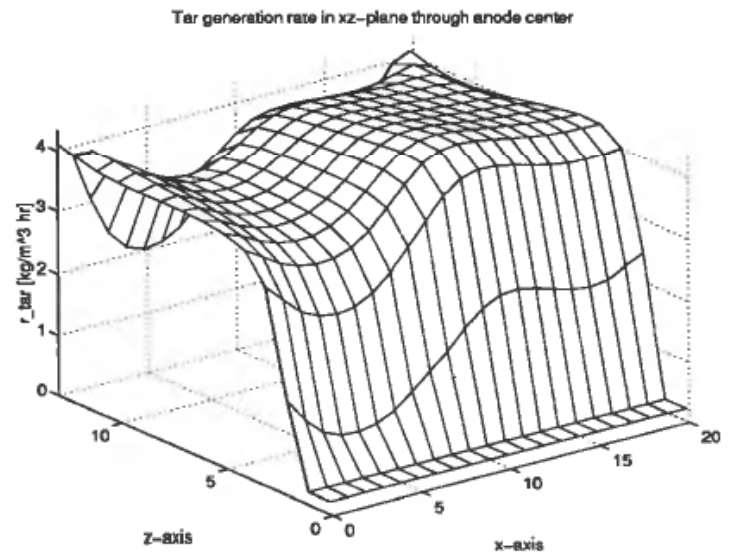

Figure 20. Tar volatile generation in the centre ( $x z$-plane) of the anodes after $94 \mathrm{~h}$. 
model for the gas equations. The control volume approach was used for deriving the numerical model, and integration of the pit temperature field equations was performed by the application of Euler's method. Compared to other explicit integration schemes, the application of Euler's method works well in relation to two aspects:

- Accuracy: The accuracy of Euler's method is good enough since the derivatives of the temperature field are very smooth. Tests with Runge Kutta- and predictor-corrector-methods gave no improved accuracy.

- Simulation time: The stability criterion for high-order explicit integrator schemes are comparable to the stability criterion for Euler's method. Therefore, application of high-order integrators increases simulation time several times since the most time consuming part of the code is the calculation of the derivatives.

Comparison of explicit and implicit schemes on this problem has not been done. However, the application of an implicit integration scheme would necessitate simultaneous solution of a large number of non-linear equations. This is often a very time-consuming operation.

The solution procedure of alternating solution of gas- and solids-equations has also been used elsewhere (Bourgeois et al. 1990).

\section{Further work}

At this stage, the main structure of the ring furnace model is established but more detailed descriptions of both gas and anode phenomena are possible. The model is supposed to be used for furnace response prediction with respect to both geometric and operational changes. Some extensions may be needed to reach this goal:

- At present, there is no model of air inleakage. This is an important phenomenon which has severe impact on the heat balance of the furnace.

- Instantaneous and ideal combustion of methane and hydrogen has been proved to be a good approximation. However, this is not the case for the tar volatiles. Rate laws for the tar combustion exist in the literature and should be included in the model for a more realistic conversion of the energy from the tar volatiles.

- The ultimate goal of anode baking is to arrive at the best possible uniformity of the quality of the anodes in a section. The modeling of anode properties must be based on a detailed model of binder pitch pyrolysis. Since anode quality is not uniquely defined in the literature, efforts to establish an anode quality concept also seems necessary.

- Until now, only the three dimensional temperature profile has been calculated. The temperature profile causes a distributed rate of volatile release within the anode charge and thus a distributed volatile pressure within the anode blocks and packing coke bed. Due to thermal expansion and contraction of the anodes during baking, there is a build-up of thermal stresses in the anodes. Both internal volatile pressure as well as thermal stresses may lead to anode quality deterioration. Studies of pressure and thermal stress profiles have been discussed by Böttger (1990) qualitatively; but more thorough investigations seem necessary.

- So far, literature data and several assumptions have been used to obtain parameters for the model. Studies on model sensitivity to parameter changes have not yet been performed. When the most critical parameters have been determined, these parameters can probably be tuned by the application of experimental data on a real furnace. 
- Nominal gas flow input conditions for a section are used in the simulations. The model could be used as a building block in an extended simulator for a whole fire-train where the output from one section serves as gas flow input to the downstream section.

\section{ACKNOWLEDGMENTS}

This work was financed by Hydro Aluminium Årdal Verk under a doctoral scholarship and this financial support is gratefully acknowledged. Special thanks are expressed to Trygve Foosnæs for interesting discussions on carbon technology and Kjell Arne Nerland and Georg R. Neumann for fruitful discussions on ring furnace design and routine operation.

\section{REFERENCES}

BiRd, B. R., STEWARD, W. E. and LightFOOT, E. N. (1960). Transport phenomena (John Wiley $\&$ Sons, New York).

BÖTTGER, C. (1990). Ansätze für Mathematische Modellierung des Brennprozesses von Großformatigen Feinkörnigen Graphitwerkstoffen, Vol. A 803 of Freiberger Forschungshefte A. Grundstoff-Verfahrenstechnik-Brennstofftechnik (VED Deutcher Verlag für Grundstoffindustrie, Leipzig), pp. 71-84.

Bourgeois, T., Bui, R. T., ChareTte, A., SAdler, B. A. and Thomsett, A. D. (1990). Computer simulation of a vertical ring furnace, in C. M. Bickert (ed.), Light Metals 1990: Proc. of the technical sessions presented by the TMS Light Metals Committee at the 119th AIME Annual Meeting, The Metallurgical Society of AIME, Anaheim, California, pp. 547-552.

Bui, R. T., ChARETTE, A. and BourGeoIs, T. (1984). Simulating the process of carbon anode baking used in the aluminium industry, Metallurgical Transactions B, 15B, 487-492.

Bui, R. T., CHARETTE, A. and Bourgeols, T. (1987). Performance analysis of the ring furnace used for baking industrial carbon electrodes, The Canadian Journal of Chemical Engineering, 65, 96-101.

Bui, R. T., Peter, S., Charette, A., Tomsett, A. D. and Potocnik, V. (1992). Reidhammer furnace: Under-lid heat transfer analysis, in E. R. Cutshall (ed.), Light Metals 1992: Proc. of the technical sessions presented by the TMS Light Metals Committee presented at the 121st TMS Annual Meeting, The Metallurgical Society of AIME, San Diego, California, pp. 894-901.

Dernedde, E., Charette, A., Bourfeois, T. and Castonguay, L. (1986). Kinematic phenomena of the volatiles in ring furnaces, in R. E. Miller (ed.), Light Metals 1986: Proc. of the technical sessions presented by the TMS Light Metals Committee at the 115th TMS Annual Meeting, The Metallurgical Society of AIME, New Orleans, Louisiana, pp. 589-592.

Froment, G. F. and BISCHOFF, K. B. (1990). Chemical reactor analysis and design, 2 edn (John Wiley \& Sons, New York) ISBN 0-741-51044-0.

Furman, A. and Martirena, H. (1980). A mathematical model simulating an anode baking furnace, in C. J. McMinn (ed.), Light Metals 1980: Proc. of the technical sessions sponsored by the TMS Light Metals Committee at the 109th AIME Annual Meting, The Metallurgical Society of AIME, Las Vegas, Nevada, pp. 545-552. ISBN 0-89520-359-6.

HURLEN, J., LID, O., NATERSTAD, T. and UTNE, P. (1981). Operation characteristics for a vertical flue ring furnace, in G. M. Bell (ed.), Light Metals 1981: Proc. of the technical sessions sponsored by the TMS Light Metals Committee at the 110th AIME Annual Meeting, February 22-26, The Metallurgical Society of AIME, Chicago, Illinois, pp. 569-581. ISBN 0-89520-359-6.

INCOPEIRA, F. P. and DEWITT, D. P. (1990). Introduction to heat transfer (John Wiley \& Sons, New York).

JAKOBSEN, O., LID, O. and SCHREINER, P. A. (1987). A new ring furnace concept: Design and operation, in R. D. Zabreznik (ed.), Light Metals 1987: Proc. of the technical sessions sponsored by the TMS Light Metals Committee at the 116th Annual Meeting. The Metallurgical Society of AIME, Denver, Colorado, pp. 497-503.

JONES, S. S. and BART, E. F. (1990). Binder for the ideal anode carbon, in C. M. Bickert, (ed.), Light Metals 1990: Proc. of the technical sessions presented by the TMS Light Metals 
Committee at the 119th AIME Annual Meeting, The Metallurgical Society of AIME, Anaheim, California, pp. 611-627.

KELLER, F. and DisSELHORST, J. H. M. (1981). Modern anode furnace developments, in G. M. Bell (ed.), Light Metals 1981: Proc. of the technical sessions sponsored by the TMS Light Metals Committee at the 110th AIMEAnnual Meeting, The Metallurgical Society of AIME, pp. 611-621. ISBN 0-89520-359-6.

KREITH, F. and BLACK, W. Z. (1980). Basic heat transfer (Harper \& Row, New York).

LYDERSEN, A. (1983). Mass transfer in Engineering practice (john Wiley \& Sons, New York). MoniCA, E. D. F., MARLETTO, J. and MARTIRENA, H. (1983). Combined mathematical simulation and experimental studies on a closed baking furnace, in E. M. Adkins (ed.), Light Metals 1983: Proc. of the technical sessions sponsored by the TMS Light Metals Committee at the 112th AIME Annual Meeting, The Metallurgical Society of AIME, Atlanta, Georgia, pp. 805-817. ISBN 0-89520-359-6.

PatankaR, S. V. (1980). Numerical Heat Transfer and Fluid Flow (Hemisphere Publishing Corporation. McGraw Hill Book Company). ISBN 0-07-048740-5.

Perry, R. H. and GreEN, D. W. (1984). Perry's Chemical Engineers' Handbook, 6 edn (McGraw Hill Book Company) ISBN 0-07-Y66482-X.

Reid, R. C., Praunitz, J. M. and Poling, B. E. (1988). The properties of gases and liquids (McGraw-Hill, New York).

STEVENSON, D. T. (1988). Anode baking furnace hydrodynamic flue modeling, in L. G. Boxall (ed.), Light Metals 1988: Proc. of the technical sessions by the TMS Light Metals Committee at the 117th TMS Annual Meeting, The Metallurgical Society of AIME, Phoenix, Arizona, pp. 307-314. ISBN 0-89520-359-6.

Tremblay, F. and Charette, A. (1988). Cinétique de dégagement des matiéres volatiles de la pyrolyse d'electrodes de carbone industrielles, The Canadian Journal of Chemical Engineering, 6 (2), 86-96.

WiLKENING, S. (1993). Die Aluminiumshütte alouette-unter besonderer Berücksichtigung der Anodenfertigung, Erzmetall, 46 (9), 500-506.

\section{Nomenclature}

Subscripts

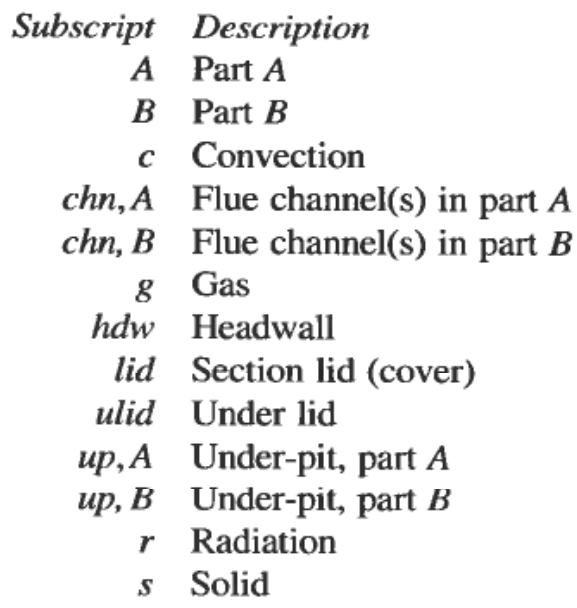

Symbols

$\begin{array}{rll}\text { Roman letters } & \text { Description } & \text { Dimension } \\ A, A_{g}, A_{s} & \text { Surface cross section } & \mathrm{m}^{2} \\ c_{p} & \text { Heat capacity } & \mathrm{J} / \mathrm{kgK} \\ D_{h} & \text { Hydraulic diameter } & \mathrm{m} \\ E_{i} & \text { Apparent activation energy in model for volatiles } & \mathrm{J} / \mathrm{molK} \\ f & \text { Moody friction factor for pipes } & \end{array}$


$f_{0 . i}$ Initial fraction of volatile component $i$ in green anode

$\mathscr{F}$ Radiation factor

$\mathscr{F}_{g s} \quad$ Radiation factor for radiation between gas and solid surfaces

$\mathscr{F}_{n} \quad$ Radiation factor for radiation between solid surfaces 1 and 2

$g_{A} \quad$ Mass flow- of gas to vertical flues part $A$ per length in direction of flow

$\mathrm{kg} / \mathrm{ms}$

$g_{B} \quad$ Mass flow-of gas from vertical flues part $B$ - per length in direction of flow

$\mathrm{kg} / \mathrm{ms}$

$g_{f}$ Mass flow of fuel (per length in direction of gas flow) into headwall

$\mathrm{kg} / \mathrm{ms}$

$g_{v, i}$ Volatile mass flow per length of flue channel

$\mathrm{kg} / \mathrm{ms}$

$G$ Mass flow

$\mathrm{kg} / \mathrm{s}$

$G_{A, i}$ Mass flow to under-lid zone from the vertical flues in part $A$

$G_{f}$ Under-lid flue mass flow

$\mathrm{kg} / \mathrm{s}$

$u$ Specific enthalpy

$\mathrm{kg} / \mathrm{s}$

$\mathrm{J} / \mathrm{kg}$

$\mathrm{W} / \mathrm{m}^{2} \mathrm{k}$

$h_{c}$ Convective heat transfer coefficient

$\mathrm{J} / \mathrm{kg}$

$h_{g, B} \quad$ Specific enthalpy for gas at outlet of vertical flues in part $B$

$\mathrm{J} / \mathrm{kg}$

$k$ Thermal conductivity

$\mathrm{W} / \mathrm{mK}$

$k_{0, i}$ Pre-exponential factor in Arrhenius-law for volatiles

$1 / \mathrm{hr}$

$M$ Molar mass

$\mathrm{g} / \mathrm{mol}$

$n_{i}$ Apparent reaction order in model for volatiles

$q^{\prime \prime}$ Total heat flux (convective and radiative)

$\mathrm{J} / \mathrm{sm}^{2}$

$q_{c}^{\prime \prime}$ Convective heat flux

$\mathrm{J} / \mathrm{sm}^{2}$

$q_{r}^{\prime \prime} \quad$ Radiative heat flux

$\mathrm{J} / \mathrm{sm}^{2}$

$Q$ Total heat transfer per unit length in direction of gas flow

$\mathrm{W} / \mathrm{m}$

$\tilde{Q}$ Heat transfer term in energy equation

$\mathrm{W} / \mathrm{m}^{3}$

$r_{i}$ Rate of emission of volatile component $i$

$\mathrm{kg} / \mathrm{m}^{3} \mathrm{~kg}$

$R$ Universal gas constant

$8 \cdot 315$

$\mathrm{J} / \mathrm{mol} \mathrm{K}$

$S$ Source term

$\mathrm{W} / \mathrm{m}^{3}$

$T$ Temperature

$\mathrm{K}$

$T_{0}$ Reference temperature $\mathrm{K}$

$v$ Gas velocity

$\mathrm{m} / \mathrm{s}$

$u$ Specific internal energy

$\mathrm{J} / \mathrm{kg}$

$\mathrm{m}^{3}$

$V_{\text {ulid }}$ Volume underlid

$X_{i}$ Fractional conversion of volatiles

$x, y, z$ Spatial coordinate directions

m

$y_{i} \quad$ Mass fraction of gas component $i$ 
Greek letters Description

$\alpha$ Absorptivity (total radiation property)

$\alpha$ Coefficient of thermal expansion

$\Delta \epsilon$ Correction for gas emissivity

$\Delta H_{f} \quad$ Fuel oil combustion enthalpy

$\Delta h_{v, i}$ Combustion enthalpy of volatile $i$

Dimension

$\Delta x, \Delta y, \Delta z$ Differential increments in space

$\eta$ Viscosity

$\epsilon_{g}$ Emissivity of combustion gas

$\epsilon_{s}$ Emissivity of solid materials

$\rho$ Density Reflectivity (total radiation property)

$\rho_{0} \quad$ Density at reference temperature $T_{0}$

$1 /{ }^{\circ} \mathrm{C}$

$\mathrm{J} / \mathrm{kg}$

$\mathrm{J} / \mathrm{kg}$

$\mathrm{m}$

$\mathrm{kg} / \mathrm{ms}$

$\sigma$ Stefan-Boltzmann constant

$\mathrm{kg} / \mathrm{m}^{3}$

$\tau$ Transmissivity

$\mathrm{kg} / \mathrm{m}^{3}$

$5 \cdot 670 \cdot 10^{-18}$

$\mathrm{W} / \mathrm{m}^{2} \mathrm{~K}^{4}$

Dimensionless numbers

For flow in a pipe with diameter $d$, the following dimensional numbers can be defined:

$\begin{array}{lll}\text { Number } & \text { Formula } & \text { Description } \\ \mathrm{Nu} & h_{c} d / k & \text { Nusselt number } \\ \mathrm{Pe} & \rho v d / D & \text { Peclet number } \\ \mathrm{Pr} & c_{p} \eta / k & \text { Prandtl number } \\ \mathrm{Re} & d v \rho_{g} / \eta & \text { Reynolds number }\end{array}$

